\title{
Quantitative characteristics, regeneration status, Physicochemical soil properties within and at different distance of abandoned skid trails in the Hyrcanian forests.
}

Pouya Abbas-Panah

Urmia University

Seyed Rostam Mousavi Mirkala ( $\sim$ r.mousavi@urmia.ac.ir )

Mehrdad Nikooy

University of Guilan

J.Eshaghi Rad

Urmia University

\section{Research}

Keywords: Harvesting, forest restoration, Shafarood forest, regeneration, skid trail

Posted Date: June 22nd, 2020

DOI: https://doi.org/10.21203/rs.3.rs-26785/v2

License: (c) (i) This work is licensed under a Creative Commons Attribution 4.0 International License.

Read Full License 
The authors have withdrawn this preprint from Research Square 